\title{
Layer 6 Corticothalamic Neurons Activate a Cortical Output Layer, Layer $5 a$
}

\author{
Juhyun Kim, ${ }^{1}$ Chanel J. Matney, ${ }^{1}$ Aaron Blankenship, ${ }^{2}$ Shaul Hestrin, ${ }^{2}$ and ${ }^{1}$ Solange P. Brown ${ }^{1}$ \\ ${ }^{1}$ Solomon H. Snyder Department of Neuroscience, Johns Hopkins University School of Medicine, Baltimore, Maryland 21205, and ${ }^{2}$ Department of \\ Comparative Medicine, Stanford University School of Medicine, Stanford, California 94305
}

Layer 6 corticothalamic neurons are thought to modulate incoming sensory information via their intracortical axons targeting the major thalamorecipient layer of the neocortex, layer 4, and via their long-range feedback projections to primary sensory thalamic nuclei. However, anatomical reconstructions of individual layer 6 corticothalamic (L6 CT) neurons include examples with axonal processes ramifying within layer 5, and the relative input of the overall population of L6 CT neurons to layers 4 and 5 is not well understood. We compared the synaptic impact of L6 CT cells on neurons in layers 4 and 5. We found that the axons of L6 CT neurons densely ramified within layer $5 \mathrm{a}$ in both visual and somatosensory cortices of the mouse. Optogenetic activation of corticothalamic neurons generated large EPSPs in pyramidal neurons in layer 5a. In contrast, excitatory neurons in layer 4 exhibited weak excitation or disynaptic inhibition. Fast-spiking parvalbumin-positive cells in both layer 5a and layer 4 were also strongly activated by L6 CT neurons. The overall effect of L6 CT activation was to suppress layer 4 while eliciting action potentials in layer 5a pyramidal neurons. Together, our data indicate that L6 CT neurons strongly activate an output layer of the cortex.

Key words: corticothalamic; inhibitory interneurons; layer 4; layer 5; somatosensory cortex; visual cortex

\section{Introduction}

Corticothalamic neurons in layer 6 of the neocortex are thought to shape the neural response to incoming sensory information in a context-dependent manner, modulating receptive-field properties to enhance behaviorally relevant information (Sherman, 2005; Sillito et al., 2006; Briggs and Usrey, 2008; Thomson, 2010; Harris and Mrsic-Flogel, 2013). In addition to providing feedback to the sensory thalamus, these neurons are thought to influence the cortical response to sensory input through their intracortical axonal projections to the major thalamorecipient layer, layer 4 (L4; Ahmed et al., 1994; Stratford et al., 1996; Guillery and Sherman, 2002; Binzegger et al., 2004; Sherman, 2005; Sillito et al., 2006; Briggs and Usrey, 2008; Thomson, 2010; Harris and Mrsic-Flogel, 2013). Although the standard view of the corticothalamic system is that the primary intracortical target of layer 6 corticothalamic (L6 CT) neurons is L4, anatomical reconstructions of individual L6 CT neurons include examples of neurons with axonal pro-

Received April 2, 2014; revised June 5, 2014; accepted June 9, 2014.

Author contributions: J.K., S.H., and S.P.B. designed research; J.K., C.J.M., and A.B. performed research; J.K., S.H., and S.P.B. analyzed data; J.K., S.H., and S.P.B. wrote the paper.

This work was supported by the National Eye Institute (EY012114), by Johns Hopkins and by the National Institutes of Neurological Diseases (NS050274). J.K. was supported by a National Research Foundation of Korea Fellowship (NRF-2011-357-E00005). C.J.M. was supported by a Predoctoral Fellowship from the National Science Foundation and an NIH Training Grant (5T32EY017203). We thank M. Proskurin, E. M. Schulteis, D. Kim, D. F. Gill, and R. R. Callen for technical assistance; B. K. Harvey and the National Institute of Drug Abuse Optogenetics and Transgenic Technology Core, and K. Deisseroth for viral constructs.

The authors declare no competing financial interests.

Correspondence should be addressed to Dr Solange Brown, Solomon H. Snyder Department of Neuroscience, Johns Hopkins School of Medicine, WBSB 906, 725 North Wolfe Street, Baltimore, MD 21205. E-mail: spbrown@jhmi.edu.

DOI:10.1523/JNEUROSCI.1325-14.2014

Copyright $\odot 2014$ the authors $\quad 0270-6474 / 14 / 349656-09 \$ 15.00 / 0$ cesses ramifying within layer 5 (L5), the principal output layer of the cortex (Katz, 1987; Zhang and Deschênes, 1997; Thomson, 2010; Feldmeyer, 2012). However, the relative anatomical and functional input of L6 CT cells to L4 and L5 is not known.

The identity of the cell types in L4 and L5 targeted by the intracortical axons of L6 CT neurons is also not clear. Recent work suggests that L6 CT neurons synapse onto inhibitory fastspiking (FS) neurons which mediate the widespread response suppression seen in visual cortex following L6 CT neuron activation (Olsen et al., 2012; Bortone et al., 2014). Although quantitative studies using electron microscopy initially suggested that L6 CT neurons preferentially target inhibitory neurons within L4, more recent studies indicate that they synapse onto both excitatory and inhibitory neurons (McGuire et al., 1984; White and Keller, 1987; Somogyi, 1989; Ahmed et al., 1994, 1997; Anderson et al., 1994; Staiger et al., 1996; Binzegger et al., 2004). The synaptic targets of L6 CT neurons within L5 remain largely unexplored.

To determine the relative synaptic impact of L6 CT cells on neurons in layers 4 and 5, we first determined the laminar position of the intracortical processes of the population of L6 CT neurons. We found that L6 CT neurons densely ramified within layer 5a (L5a) in both visual and somatosensory cortices. Optogenetic stimulation of L6 CT neurons elicited action potentials in excitatory neurons in L5a but not in layer 4. In contrast, L6 CT neurons strongly activated inhibitory FS interneurons in both L5a and L4. This L6 CT input to inhibitory neurons was cell-typespecific as L6 CT cells provided little input to somatostatinpositive (SOM) inhibitory interneurons in L5a. The net effect of this circuit organization was to evoke action potentials in L5a pyramidal neurons while suppressing excitatory neurons in L4 
following L6 CT stimulation. Together, our data demonstrate that the dense axonal projection of L6 CT neurons to L5a strongly activates both excitatory pyramidal cells and inhibitory FS cells of an output layer of the cortex.

\section{Materials and Methods}

All experiments were conducted in accordance with the procedures established by the Johns Hopkins Animal Care and Use Committee or the Administrative Panel on Laboratory Care at Stanford University. The following mouse lines were used: Neurotensin receptor-1 Cre recombinase line (Ntsr1-Cre, GENSAT 220, Mutant Mouse Regional Resource Center 017266-UCD, RRID:IMSR_MMRRC:017266; Gong et al., 2007), loxP-STOP-loxP-channelrhodopsin-2-EYFP Cre-dependent line (ChR2EYFP, Ai32, Allen Brain Institute, Jackson 012569, RRID:IMSR_JAX: 012569; Madisen et al., 2012), loxP-STOP-loxP-tdTomato Cre reporter lines (Ai9 and Ai14, Allen Brain Institute, Jackson 007905 and 007908, RRID:IMSR_JAX:007905 and RRID:IMSR_JAX:007908; Madisen et al., 2010), loxP-STOP-loxP-synaptophysin-tdTomato Cre reporter line (Ai34, Allen Brain Institute, Jackson 012570, RRID:IMSR_JAX:012570), Gad67-GFP knock-in line ( $\Delta$ neo, RRID:IMSR_RBRC03674; Tamamaki et al., 2003), Gad67-GFP transgenic line (G42, Jackson 007677, RRID: IMSR_JAX:007677; Chattopadhyaya et al., 2004) and the GIN transgenic line (Jackson 003718, RRID:IMSR_JAX:003718; Oliva et al., 2000) on a mixed background.

Injection of retrograde tracers and viral vectors for anatomical analysis. To identify corticothalamic and corticotectal neurons, retrograde neuronal tracers were injected into targeted nuclei of the thalamus or the superior colliculus of Ntsr1-Cre;tdTomato mice. Briefly, mice of either sex, ranging from postnatal day 16 (P16) to P80 were anesthetized with ketamine $(50 \mathrm{mg} / \mathrm{kg})$, dexmedetomidine $(25 \mu \mathrm{m} / \mathrm{kg})$ and the inhalation anesthetic, isoflurane. Animals were placed in a custom-built stereotaxic frame and anesthesia was maintained with isoflurane. A small craniotomy was performed and $30 \mathrm{nl}$ of neuronal tracer was pressure-injected into one site in the lateral geniculate nucleus (LGN) or the ventral posteromedial nucleus (VPM) of the thalamus through a glass pipet (13-25 $\mu \mathrm{m}$ tip diameter) using stereotaxic coordinates derived from a mouse brain atlas (Franklin and Paxinos, 2007) and empirically confirmed. To retrogradely label corticotectal neurons, up to 16 sites were injected in the superior colliculus. Four tracers were used with similar results: red and green Retrobeads (Lumafluor), and red and green Alexa-conjugated Cholera toxin B (AlexaFluor 488 and AlexaFluor 555 CTB, Invitrogen). To reveal the location of thalamocortical axons in the cortex, a lentiviral vector [VSVG.HIV.SIN.Synapsin.ChR2(H134R).EYFP.WP, p1871, University of Pennsylvania Vector Core] was injected into the LGN or VPM using similar procedures. Buprenorphine $(0.05 \mathrm{mg} / \mathrm{kg})$ was administered to all animals postoperatively. Animals injected with retrograde tracers were killed 5-10 d after surgery whereas animals injected with the viral vectors were killed up to 7 months postoperatively. Whole brains were removed and placed in a solution of $4 \%$ paraformaldehyde in $0.01 \mathrm{M}$ PBS for $>2 \mathrm{~h}$. Coronal, thalamocortical, or parasagittal sections cut on a $30^{\circ}$ ramp were prepared on a vibratome (100 $\mu \mathrm{m}$, VT-1000S, Leica), then mounted using Vectashield mounting medium (Vector Laboratories) and visualized either on an epifluorescence microscope (Axiophot, Zeiss) using $2.5 \times(0.075 \mathrm{NA}), 5 \times(0.15 \mathrm{NA}), 10 \times(0.25 \mathrm{NA})$, or $20 \times(0.5 \mathrm{NA})$ objectives or on a confocal microscope (LSM 510, Zeiss) using $5 \times(0.15$ $\mathrm{NA}), 10 \times(0.3 \mathrm{NA})$, or $20 \times(0.8 \mathrm{NA})$ objectives. To confirm the location of the barrels, some sections from Ntsr1-Cre;synaptophysin-tdTomato mice were subjected to cytochrome $\mathrm{C}$ oxidase/diaminobenzidine staining. To enhance the signal from ChR2-EYFP, some sections were subjected to immunohistochemistry (1:300, chicken anti-GFP antibody, GFP-1020, Aves, RRID:AB_10000240, and 1:300 AlexaFluor 488conjugated goat anti-chicken antibody, Life Technologies, A11039, RRID:AB_10563770). NeuN + neurons were revealed using standard immunohistochemistry (1:300, mouse anti-NeuN antibody, MAB377, Millipore, RRID:AB_2298772, and 1:300 AlexaFluor 647-conjugated goat anti-mouse, Life Technologies, A21235, RRID:AB_10562370). Counting of corticothalamic, Ntsr1+ and NeuN + neurons was performed on single-plane confocal images.
Expression of channelrhodopsin-2. To express channelrhodopsin-2 (ChR2) in Ntsr1 + neurons, three strategies were used. First, Ntsr1-Cre mice were crossed with Ai32 mice (loxP-STOP-loxP-ChR2-EYFP) to produce mice in which ChR2-EYFP was expressed in all Cre-expressing neurons. Second, to limit expression to Cre-expressing neurons in the neocortex, Cre-dependent adeno-associated viral constructs (AAV2/9 CAG-FLEX-hChR2(H134R)-tdTomato, AAV 2/5 EF1a-DIO-hChR2 (H134R)-eYFP-WPRE, AAV2/5 EF1a-DIO-hChR2(H134R)-mCherryWPRE) were injected into the somatosensory cortex of P26-P93 Ntsr1Cre, Ntsr1-Cre; $\Delta$ neo or Ntsr1-Cre; GIN mice using the same approaches as described above for the tracer injections. In two cases, AAV2/9 CAGFlex-ChR2-tdTomato was injected in P2 Ntsr1-Cre; $\Delta$ neo mouse pups. Briefly, anesthesia was induced via hypothermia. A 35 gauge needle attached to a syringe (NanoFil, World Precision Instruments) was positioned by eye above the cortex, advanced until it punctured the skin and skull, and then retracted to $600 \mu \mathrm{m}$ below the surface of the skin. After waiting $3 \mathrm{~min}, 50-100 \mathrm{~nL}$ of virus was injected using a syringe pump (50 $\mathrm{nL} / \mathrm{min}, \mathrm{UMP} 3$, World Precision Instruments). Following injection, the pups were placed on a heating pad under a heat lamp. Viral constructs were acquired from the University of Pennsylvania Vector Core, the National Institute of Drug Abuse Optogenetics and Transgenic Technology Core, and the University of North Carolina Vector Core. Different viral constructs were used due to the different fluorophores they contained. Because no significant differences in the responses were identified among the viral constructs, the results were pooled for analysis. Brain slices were prepared from mice at least 2 weeks following viral injections.

Brain slice preparation for electrophysiological recordings. After anesthetizing the mice (P15-P293) with isoflurane, the brains were rapidly removed and acute brain slices $(300 \mu \mathrm{m})$ were prepared in ice-cold sucrose solution containing the following (in mM): $76 \mathrm{NaCl}, 25 \mathrm{NaHCO}_{3}, 25$ glucose, 75 sucrose, $2.5 \mathrm{KCl}, 1.25 \mathrm{NaH}_{2} \mathrm{PO}_{4}, 0.5 \mathrm{CaCl}_{2}, 7 \mathrm{MgSO}_{4}$, pH 7.3, $310 \mathrm{mOsm}$. Slices were cut in three orientations (Integraslice $7550 \mathrm{MM}$, Campden Instruments or VT-1200s, Leica), depending on the cortical region targeted: parasagittal sections for visual and barrel cortex as well as thalamocortical slices for barrel cortex. Responses were similar whether or not the thalamus was included in the slice. After cutting, slices were incubated in warm $\left(32-35^{\circ} \mathrm{C}\right)$ sucrose for $30 \mathrm{~min}$ and then transferred to warm $\left(32-35^{\circ} \mathrm{C}\right.$ ) artificial CSF (aCSF) composed of (in mM): $125 \mathrm{NaCl}$, $26 \mathrm{NaHCO}_{3}, 2.5 \mathrm{KCl}, 1.25 \mathrm{NaH}_{2} \mathrm{PO}_{4}, 1 \mathrm{MgSO}_{4}-7 \mathrm{H}_{2} \mathrm{O}, 20 \mathrm{D}-(+)$-glucose, $2 \mathrm{CaCl}_{2}-2 \mathrm{H}_{2} \mathrm{O}, 0.4$ ascorbic acid, 2 pyruvic acid, 4 L-lactic acid, $\mathrm{pH}$ 7.3, $315 \mathrm{mOsm}$, and then allowed to cool to room temperature. Betahydroxybutyrate $(4 \mathrm{~mm})$ was added to the sucrose and recording solutions in a subset of experiments. All solutions were continuously bubbled with $95 \% \mathrm{O}_{2} / 5 \% \mathrm{CO}_{2}$.

Whole-cell recordings. Slices were transferred to a submersion chamber on an upright microscope (Zeiss FS2-Plus microscope, $40 \times$ objective, $0.8 \mathrm{NA}$ or a Zeiss AxioExaminer, $40 \times$ objective, 1.0 NA). During recordings, slices were continuously superfused $(2-4 \mathrm{ml} / \mathrm{min})$ with warm aCSF $\left(32-34^{\circ} \mathrm{C}\right)$. Neurons were visualized with a digital camera (Sensicam QE; Cooke) using either transmitted light with infrared differential interference contrast optics or epifluorescence. The orientation of the slice was verified by visualizing the apical dendrites of infragranular pyramidal neurons up to layer 1 in the area of the recordings. Glass recording electrodes (2-4 M $\Omega$ ) were filled with internal solution containing the following (in mM): $2.7 \mathrm{KCl}, 120 \mathrm{KMeSO}_{4}, 9$ HEPES, 0.18 EGTA, 4 MgATP, 0.3 NaGTP, 20 phosphocreatine(Na), pH 7.3, 295 mOsm or 2.7 $\mathrm{KCl}, 120 \mathrm{KMeSO}_{3}$, 9 HEPES, 0.18 EGTA, 4 MgATP, 0.3 NaGTP, 20 phosphocreatine $(\mathrm{Na}), \mathrm{pH}$ 7.3, $295 \mathrm{mOsm}$. Whole-cell patch-clamp recordings were obtained using Multiclamp 700A or 700B amplifiers (Molecular Devices) controlled by custom-written routines in Igor Pro (Wavemetrics) and digitized using an ITC-18 (Instrutech) using custom software written in Igor Pro (Wavemetrics). The access resistance averaged 18.66 $\mathrm{M} \Omega \pm 8.77 \mathrm{SD}$ and was not compensated. All signals were low-pass filtered at $10 \mathrm{kHz}$ and sampled at $20 \mathrm{kHz}$.

Cell-type identification. Neurons were classified by their responses to current injection in current-clamp mode and their expression of fluorescent proteins in selected mouse lines. Cortical layers were determined based on the expression pattern of the ChR2-EYFP fluorescence. Neurons seen in a band consisting of neuronal processes strongly expressing 
A

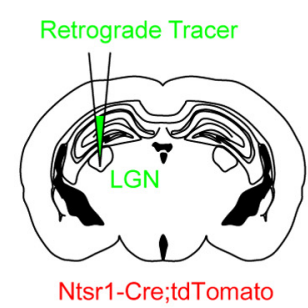

F

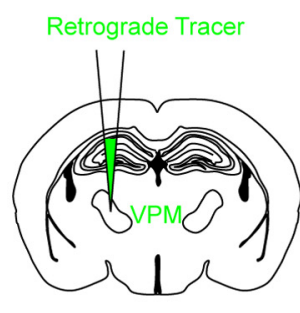

Ntsr1-Cre;tdTomato
B

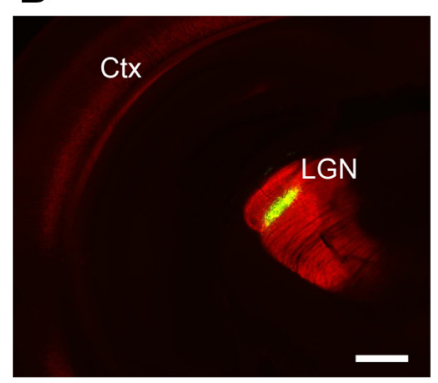

G

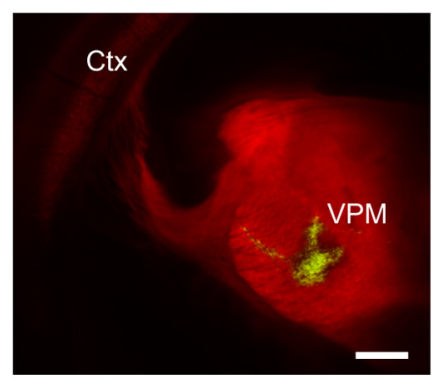

C

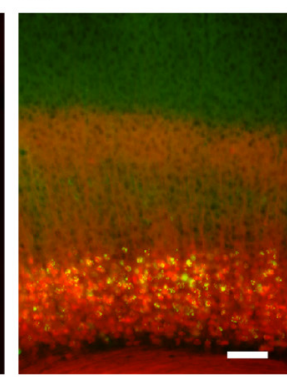

H

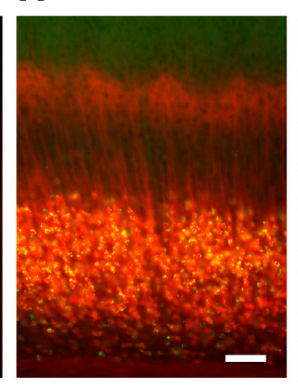

D

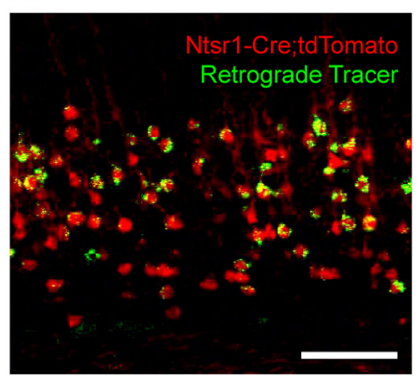

I

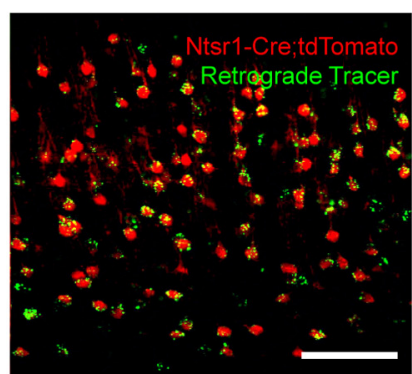

E

Beads+Ntsr1/Ntsr1

$\square$ Beads+Ntsr1/Beads

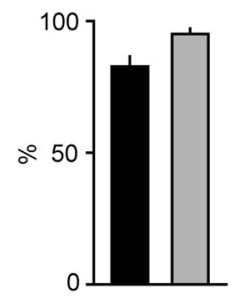

J

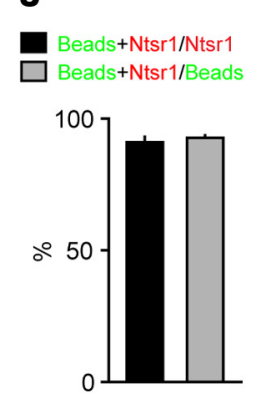

Figure 1. Cre expressing neurons in the cortex of Ntsr1-Cre mice are L6 CT neurons. $\boldsymbol{A}, \boldsymbol{F}$, Experimental configuration. Neuronal tracers were injected into the LGN $(\boldsymbol{A}, \boldsymbol{B})$ or VPM $(\boldsymbol{F}, \boldsymbol{G})$ to retrogradely label $\mathrm{L} 6 \mathrm{CT}$ neurons in visual cortex $(\boldsymbol{C}, \boldsymbol{D})$ or somatosensory cortex $(\boldsymbol{H}, \boldsymbol{I})$ of Ntsr1-Cre mice crossed with a tdTomato reporter line. Images of the injection sites ( $\boldsymbol{B}, \boldsymbol{G}$; cortex, Ctx). Low $(\boldsymbol{C}, \boldsymbol{H})$ and high-magnification $(\boldsymbol{D}, \boldsymbol{I})$ views of Ntsr1+ neurons (red) and retrogradely labeled L6 CT neurons (green) in visual cortex $(\boldsymbol{C}, \boldsymbol{D})$ and somatosensory cortex $(\boldsymbol{H}, \boldsymbol{I}) . \boldsymbol{E}, \boldsymbol{J}$, Summary data showing the overlap between Ntsr1+ neurons and neurons retrogradely labeled from the $\operatorname{LGN}(\boldsymbol{E} ; n=3$ mice) or VPM $(\boldsymbol{J} ; n=3$ mice). In visual cortex, $82.6 \pm 3.8 \%$ of Ntsr1 + cells were retrogradely labeled, and $95.0 \pm 2.1 \%$ of retrogradely labeled L6CT neurons were Ntsr $1+$. In the somatosensory cortex, $91.0 \pm 2.0 \%$ of Ntsr $1+$ cells were retrogradely labeled, and $92.7 \pm 0.9 \%$ of retrogradely labeled L6 CT neurons were Ntsr1+. Scale bars: (in B, G) $500 \mu \mathrm{m}$; (all other images) $100 \mu \mathrm{m}$.

EYFP were identified as L5a cells; cells located directly above the florescent band were identified as L4 neurons. In slices of the barrel cortex, the location of the barrels viewed under infrared-differential interference contrast (IR-DIC) was used to confirm the location of the targeted cells. Results from neurons within each layer were pooled, as there was no significant relationship between the response properties and the laminar location within the layer. When comparing synaptic responses evoked in L4 and L5a, neurons with interspike intervals of $<25$ ms measured in response to the smallest current step generating at least four action potentials were considered FS cells and were excluded from analysis. To record from interneurons, fluorescent cells were targeted in G42, $\Delta$ neo, or GIN mice crossed with Ntsr1-Cre or Ntsr1-Cre;tdTomato mice. Interneurons in $\Delta$ neo mice were classified as either FS or "other" as described above. After each recording, low-magnification images were taken $(10 \times 0.3 \mathrm{NA}$ lens or $5 \times 0.16 \mathrm{NA})$ of ChR2 reporter fluorescence and/or the barrel columns to register the position of recorded cells relative to one another and relative to the fluorescent band of Ntsr1+ processes.

Photostimulation of ChR2. ChR2 was photoactivated as previously described (Arroyo et al., 2012). Briefly, a small circle of blue light (110-315 $\mu \mathrm{m}$ diameter) was focused onto the brain slice using a fiber optic cable coupled to a blue LED ( $\sim 470 \mathrm{~nm}$, Luminous) focused onto the focal plane of a camera port with a $10 \times 0.3 \mathrm{NA}$ lens. Ten light pulses (1-3 ms each, $6-600 \mathrm{~mW} / \mathrm{mm}^{2}$ ) were delivered through the $40 \times$ objective at 10 Hz. Except for Figures 4 and 6, the light intensity was adjusted so as not to evoke action potentials in the recorded neurons. For most recordings, the LED illumination was centered over layer 6, directly below the recorded cells in layers 4 and 5 . In some recordings, the LED illumination was centered between the two recorded cells in cell pairs or directly over the recorded cell in single-cell recordings.

Data analysis. All data analysis was performed in Igor Pro (Wavemetrics) and Excel (Microsoft). The resting membrane potential (RMP) was measured after whole-cell configuration was achieved, and neurons with an RMP greater than $-60 \mathrm{mV}$ were eliminated from further analysis. To assess the spiking behavior of the cell, 1 s long depolarizing (100-300 pA) and hyperpolarizing $(-100 \mathrm{pA})$ current steps were injected into the cells.
Typically, 50-100 individual traces were averaged to measure the peak amplitude of the postsynaptic potentials for each recorded pair of neurons. The peak in the $40 \mathrm{~ms}$ after stimulus onset was identified in the averaged trace, and the peak amplitude was calculated by subtracting the value at the peak from the baseline value (calculated for the period 1-6 $\mathrm{ms}$ before the first stimulus). In some experiments, $5 \mu \mathrm{M} \mathrm{CPP}$, and $5 \mu \mathrm{M}$ NBQX or $1 \mu \mathrm{M}$ tetrodotoxin (all from Tocris Bioscience) were bath applied to the slice. Data are presented as the mean \pm SEM unless otherwise noted. Unless otherwise indicated, a paired $t$ test was used to compare the two cell types in each group of paired recordings. In the figures, the statistical significance is expressed as follows: ${ }^{*} p<0.05$; ${ }^{* *} p<0.01$; or ${ }^{\star * *} p<0.001$.

\section{Results}

Intracortical location of L6 CT neuron processes

To determine the relationship between the intracortical processes of L6 CT neurons and the laminar structure of the cortex, we used a recently developed mouse line, Ntsr1-Cre, in which Cre recombinase is expressed in L6 neurons (Gong et al., 2007; Olsen et al., 2012; Bortone et al., 2014). We found a close correspondence between retrogradely labeled L6 CT cells and Ntsr1+ neurons in both visual and somatosensory cortex (Fig. 1; $93.8 \pm 1.1 \%$ of retrogradely labeled neurons were Ntsr1+, $86.8 \pm 2.7 \%$ of $\mathrm{Ntsr} 1+$ cells were retrogradely labeled, $n=6$ mice). Ntsr $1+$ cells represented $\sim 65.5 \%$ of NeuN + cells in L6 of somatosensory cortex $(176 \mathrm{Ntsr} 1+/ 273 \mathrm{NeuN}+$ cells; $n=2$ mice $)$, similar to what has previously been reported in visual cortex (Olsen et al., 2012). Based on these results, we used the Ntsr1-Cre line to probe the anatomical and functional relationship of L6 CT neurons with L4 and L5.

When the Ntsr1-Cre line is crossed with a tdTomato reporter line, a dense band of processes is seen in the middle of the cortex (Fig. 1C,H). To determine the location of this intracortical projection, we injected a lentiviral vector carrying a construct for a 
A

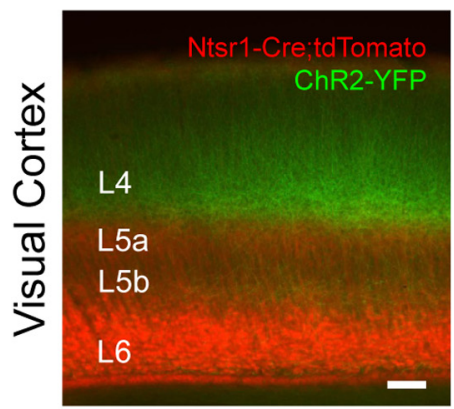

E

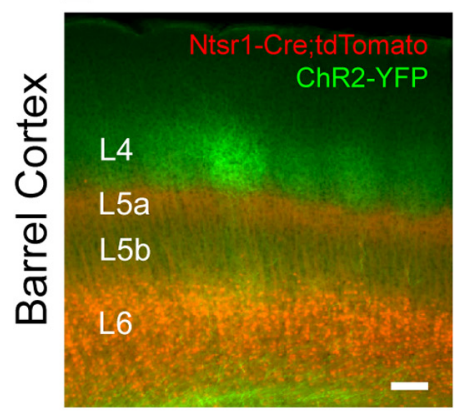

B

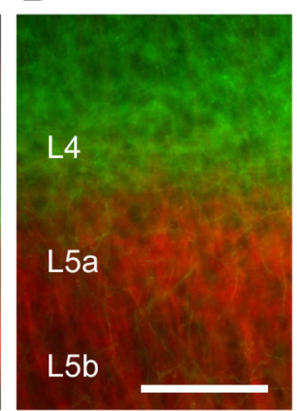

F

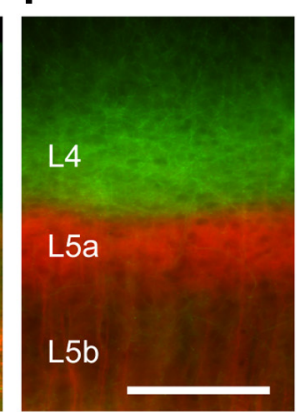

C
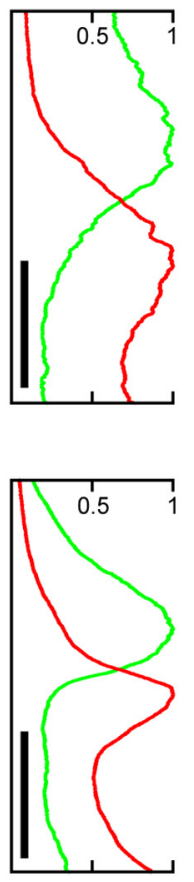

G
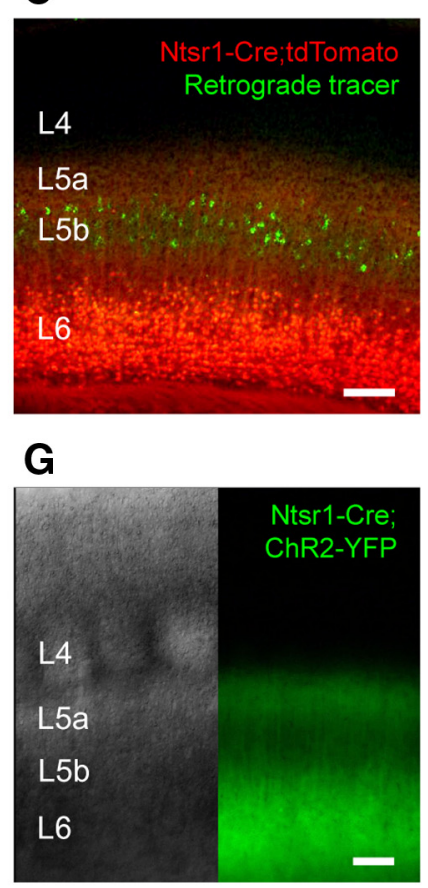

D

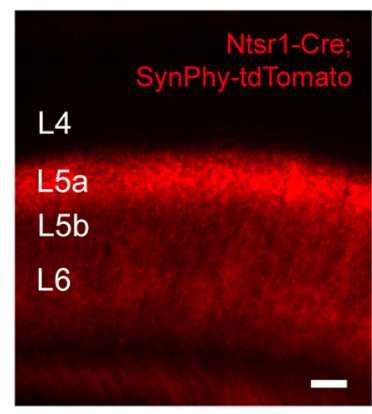

H

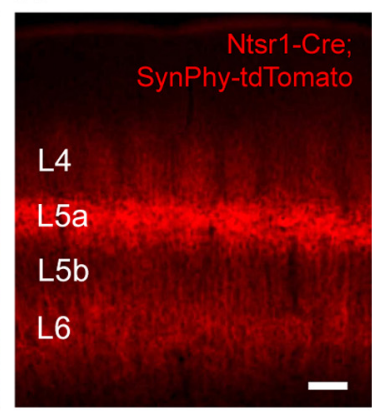

I
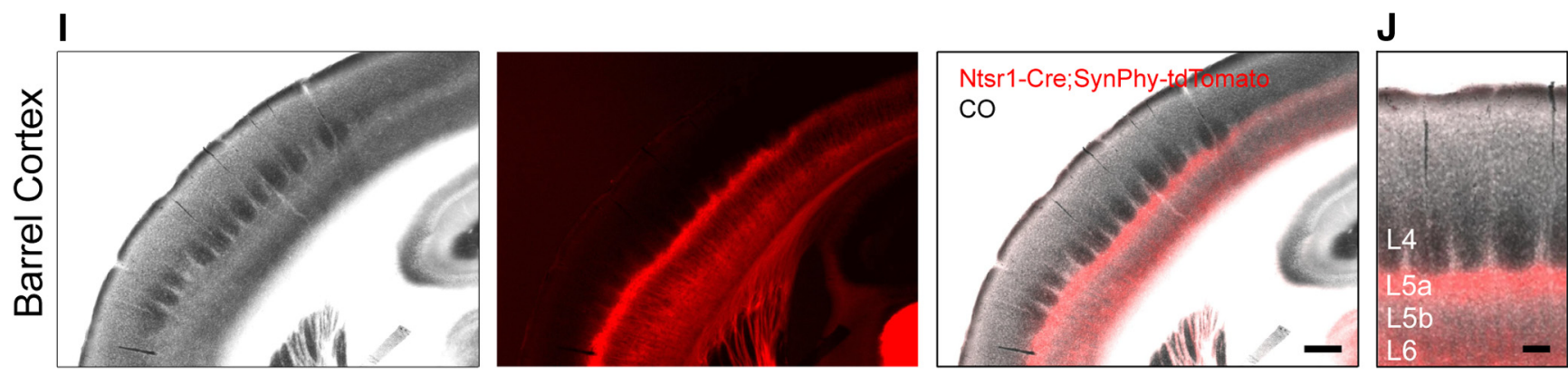

Figure 2. The axonal processes of $\mathrm{L} 6 \mathrm{CT}$ neurons primarily ramify in $\mathrm{L} 5 \mathrm{a}$. Low $(\boldsymbol{A}, \boldsymbol{E})$ and high-magnification $(\boldsymbol{B}, \boldsymbol{F})$ views of thalamocortical axons (green) and $\mathrm{L} 6 \mathrm{CT}$ neurons (red) in visual cortex $(\boldsymbol{A}, \boldsymbol{B})$ and somatosensory cortex $(\boldsymbol{E}, \boldsymbol{F})$. A normalized intensity plot centered over $L 4$ and $L 5 \mathrm{a}$ for the red and green channels averaged along the horizontal axis is shown ( $\boldsymbol{B}, \boldsymbol{F}$, right). $\boldsymbol{C}, \mathrm{L} 6 \mathrm{CT}$ neurons (red) and retrogradely labeled L5b corticotectal neurons (green) in visual cortex. G, IR-DIC (left) and epifluorescent (right) views of the same slice of barrel cortex in an Ntsr1-Cre mouse crossed with a ChR2-YFP reporter line. The axons of L6 CT neurons in visual cortex ( $\boldsymbol{D} ; n=4$ mice) and barrel cortex ( $\boldsymbol{H} ; n=9$ mice) revealed using a synaptophysin-tdTomato reporter line. Low- $(\boldsymbol{I})$ and high-magnification $(J)$ images of cytochrome $C$ oxidase-stained barrel cortex and the axonal processes of $\mathrm{L} 6$ CT neurons identified by crossing Ntsr1-Cre mice with a synaptophysin-tdTomato reporter line ( $n=3$ mice). Note that the intracortical axonal band of L6 CT neurons is located below the barrels. Scale bars: (in $I) 300 \mu \mathrm{m}$; (in all other images) $100 \mu \mathrm{m}$.

fluorescent protein into the LGN and VPM to transduce thalamocortical neurons and label thalamocortical axons terminating in L4. A dimmer fluorescence signal can also be appreciated at the L5b/L6 border or within L6. Surprisingly, the YFP-labeled thalamocortical axons within L4 were not colocalized with the tdTomato band of corticothalamic processes (Fig. $2 A, B, E-F$; LGN: $n=3$ mice, VPM: $n=3$ mice). Rather, the primary band of thalamocortical axons was centered above the major band of intracortical corticothalamic processes. These results indicate that the majority of intracortical L6 CT processes are not found in L4 but rather in L5.

To localize the lower boundary of the band of intracortical L6 CT processes, we took two approaches. First, we determined that retrogradely labeled corticotectal neurons in layer 5b (L5b) of visual cortex were located just below the band of intracortical corticothalamic processes (Fig. $2 C, n=3$ mice). Second, we compared the location of the fluorescent band with the laminar boundaries of the barrel cortex identified using IR-DIC microscopy and found that the fluorescent band largely colocalized with layer 5a (L5a; Fig. 2G), confirming that L6 CT processes are con- centrated in L5a. To determine whether the L6 CT band contained axonal processes, we used a synaptophysin-tdTomato reporter line in which the fluorescent protein is confined to axonal arbors and confirmed that the axonal processes of L6 CT neurons more densely ramified in L5a than in L4 (Fig. $2 \mathrm{D}, \mathrm{H}$ ). Revealing the location of the barrels in L4 of the somatosensory cortex with cytochrome $\mathrm{C}$ oxidase confirmed that the axonal processes of L6 CT neurons ramified largely just below the barrels in L5a (Fig. $2 I, J)$. These anatomical studies demonstrate that the axonal projection of L6 CT cells in the middle layers of the cortex primarily targets L5a.

\section{Layer 6 corticothalamic synaptic inputs to excitatory neurons} in L4 and L5a

We next compared the functional synaptic impact of the population of L6 CT neurons on cells in L4 and L5a as several recent studies have demonstrated that the densities of the presynaptic axonal arbor and the postsynaptic dendritic tree do not always correlate with their functional connectivity (Shepherd et al., 2005; Brown and Hestrin, 2009). To compare the postsynaptic 
A

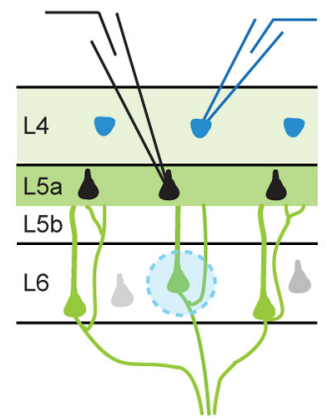

B

\author{
L5a Excitatory cell
}

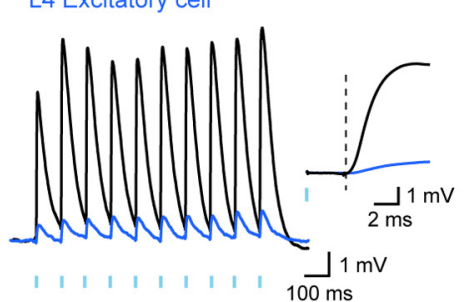

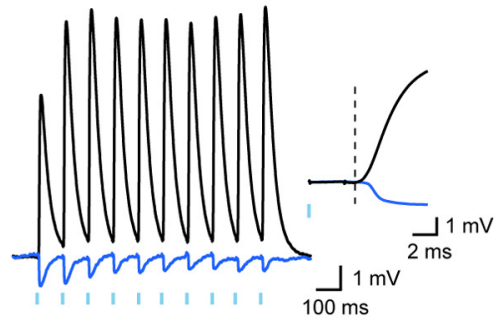

$\mathbf{F}$
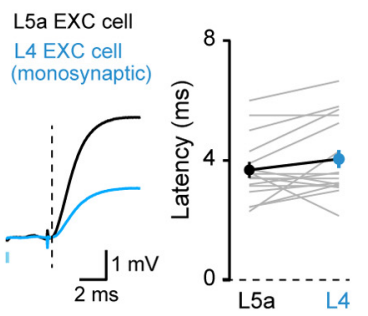

C

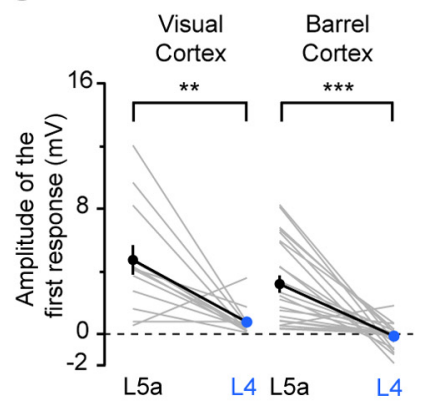

D

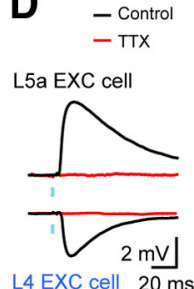

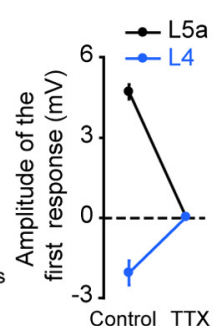
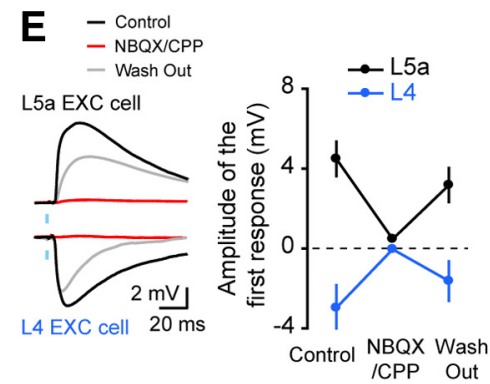

G

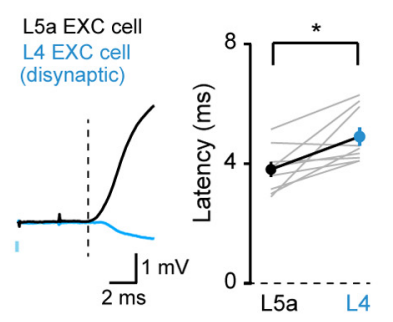

Figure 3. The synaptic impact of $L 6 C T$ neurons is markedly greater in $L 5 a$ than in $L 4 . A$, Experimental configuration. $B$, Two examples of paired recordings composed of one $L 5 a$ pyramidal neuron and one $L 4$ excitatory cell. Inset, Onset of the first responses. C, Summary data of the amplitudes of the first response for pairs of $L 4$ and L5a excitatory cells in visual cortex and barrel cortex. $D$, Single examples of responses before and during bath application of TTX (left), and summary data (right; $L 5 a: n=4$ cells; disynaptic inhibition in $L 4: n=4$ cells). $\boldsymbol{E}$, Single examples of responses before, during, and after bath application of glutamate receptor antagonists (left) and summary data (right; L5a: $n=7$ cells, disynaptic inhibition in $L 4: n=6$ cells). $\boldsymbol{F}$, Single example (left) and summary data (right) comparing the latency of the response in recorded pairs of $L 5$ a and $L 4$ excitatory neurons showing monosynaptic responses. $G$, Single example (left) and summary data (right) comparing the latency of the response in recorded pairs of $L 5 \mathrm{a}$ and $L 4$ excitatory neurons in which the $L 4$ neuron exhibited a disynaptic inhibitory response.

responses elicited in L4 and L5a by the L6 CT population, we selectively expressed ChR2 in L6 CT neurons (Fig. 2G) and simultaneously recorded from a L4 and a L5a excitatory neuron in whole-cell current-clamp configuration while photostimulating L6 CT neurons (Fig. 3A). This recording configuration allowed us to control for variations in the expression of ChR2 across animals and slices. Both L4 and L5a excitatory neurons exhibited postsynaptic responses to optogenetic stimulation of L6 CT neurons (Fig. $3 B, C$ ). These postsynaptic responses were eliminated by bath application of the sodium channel blocker, tetrodotoxin, indicating that they are action potential-dependent (Fig. 3D). Several lines of evidence indicate that L6 CT inputs predominantly target L5a rather than L4. First, the mean amplitude of the short-latency postsynaptic responses to L6 CT stimulation in L5a pyramidal neurons was markedly greater than in L4 excitatory cells of both the visual and barrel cortices (Fig. 3C; visual cortex: L5a $4.68 \pm 0.95 \mathrm{mV}, \mathrm{L} 40.69 \pm 0.26 \mathrm{mV}, n=13$ pairs, $p=0.0026$; barrel cortex: L5a $3.17 \pm 0.56 \mathrm{mV}, \mathrm{L} 4-0.18 \pm 0.15 \mathrm{mV}, n=24$ pairs, $p<0.0001)$. Second, whereas EPSPs were recorded in L5a pyramidal neurons, only $49 \%$ of L4 excitatory cells responded to optogenetic stimulation with EPSPs. The remaining L4 excitatory cells exhibited no discernible response $(16 \%, n=6)$ or predominantly inhibitory responses ( $35 \%, n=13$; Fig. $3 B$, right). Several lines of evidence indicate that the inhibition in L4 excitatory neurons is disynaptic. First, bath application of blockers of AMPA and NMDA receptors eliminated the inhibitory responses in L4 cells (Fig. $3 E$; L5a: $n=7$ cells; L4: $n=6$ cells). Second, the latency of the inhibitory responses in L4 neurons was significantly longer than the latency for the excitatory responses in L5a neurons, suggesting that these represent disynaptic inhibition (Fig. $3 F, G$ ). In those pairs in which the excitatory response dominated, the latency of the response measured in the L5a and L4 neurons was not significantly different (L5a: $3.7 \pm 0.3 \mathrm{~ms}, \mathrm{~L} 4$ : $4.1 \pm 0.3 \mathrm{~ms}, n=16$ pairs, $p=0.0943$ ) whereas in those pairs in which the L4 neuron showed a primarily inhibitory response, the latency was significantly longer in the L4 neuron (L5a: $3.8 \pm 0.3$ ms, L4: $4.9 \pm 0.3 \mathrm{~ms}, n=9$ pairs, $p=0.0122$ ). Together, these data indicate that activation of L6 CT neurons evokes much larger excitatory postsynaptic responses in L5a pyramidal neurons than in L4 excitatory cells.

Does the difference in synaptic input that we identified impact the spiking behavior of the excitatory neurons in L5a and L4? To address this question, we increased the intensity of photostimulation to L6 CT neurons and evoked action potentials in postsynaptic neurons. In all 13 recorded pairs, the L5a neuron fired action potentials whereas the L4 neuron did not (Fig. $4 ; n=13$ pairs, $p=0.0002$ ), indicating that L6 CT neuron activation can cause L5a excitatory neurons to spike and not L4 cells. Therefore, our data indicate that the population of L6 CT neurons drives L5a excitatory neurons much more strongly than those in L4.

\section{Layer 6 corticothalamic inputs to FS interneurons in L4 and L5a}

To compare the amplitude of the responses in excitatory and inhibitory neurons in both L5a and L4, we next recorded simultaneously from a FS inhibitory interneuron and a neighboring excitatory neuron while photostimulating L6 CT neurons. The amplitude of the responses was significantly greater in FS cells than in neighboring excitatory neurons both in L5a and in L4 (Fig. 5A-C, E-G; L5a: EXC $1.95 \pm 0.36 \mathrm{mV}$, FS $6.39 \pm 0.90 \mathrm{mV}$, $n=30$ pairs, $p<0.0001$; L4: EXC $-0.66 \pm 0.26 \mathrm{mV}$, FS $4.78 \pm$ $0.96 \mathrm{mV}, n=23$ pairs, $p<0.0001)$. All responses in FS cells were excitatory, even those recorded in L4, indicating that L6 CT neu- 
A

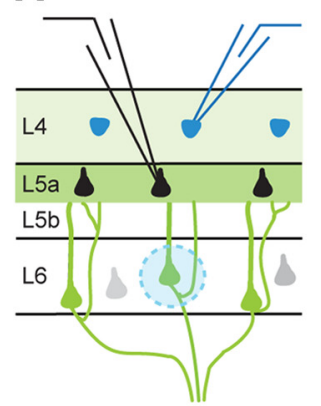

B

L5a Excitatory cell L4 Excitatory cell

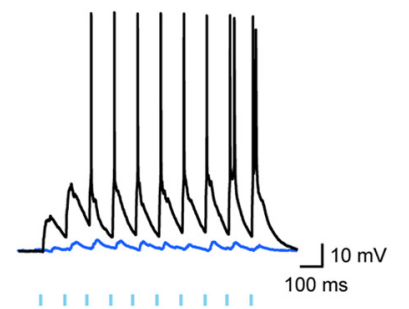

C

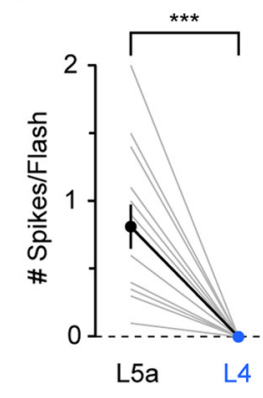

D

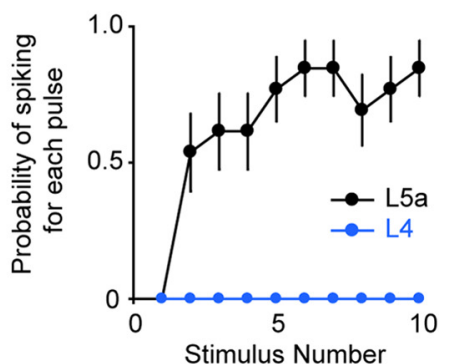

Figure 4. Activation of $L 6 C T$ neurons evokes action potentials in $L 5 a$ pyramidal neurons. $A$, Experimental configuration. $B$, Example response from a paired recording of a $L 5 a$ pyramid and a $L 4$ excitatory cell. $C$, Average number of action potentials per photostimulation elicited in each pair of $\mathrm{L} 5 \mathrm{a}$ and $\mathrm{L} 4$ neurons ( $\mathrm{L} 5 \mathrm{a}: 0.81 \pm 0.16, \mathrm{~L} 4: \mathrm{no}$ action potential elicited, $n=13$ pairs, $p=0.0002$ ). D, The average probability of firing an action potential is shown for $L 4$ and $L 5 a$ neurons for each photostimulation in the train ( $n=13$ pairs).

A

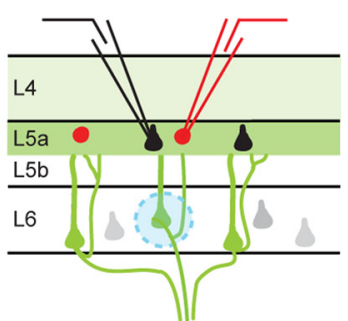

$\mathbf{E}$

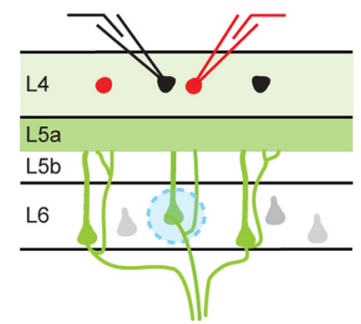

I

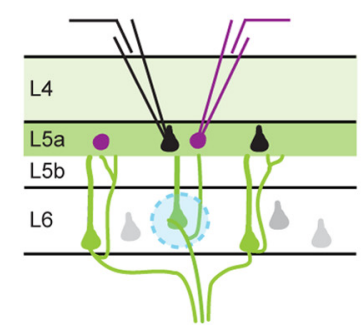

B

L5a Excitatory cell L5a FS cell

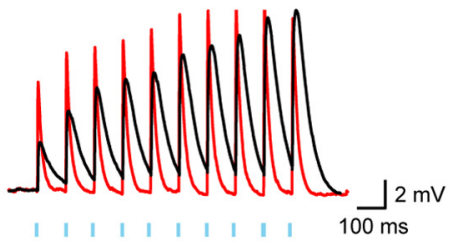

$\mathbf{F}$

L4 Excitatory cell L4 FS cell

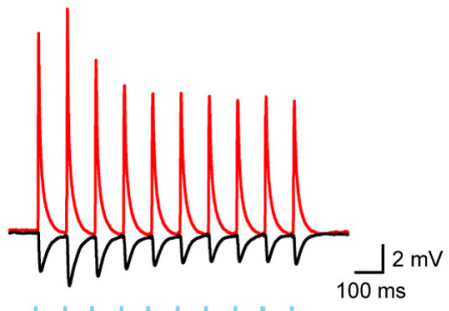

J

L5a Excitatory cell L5a SOM cell

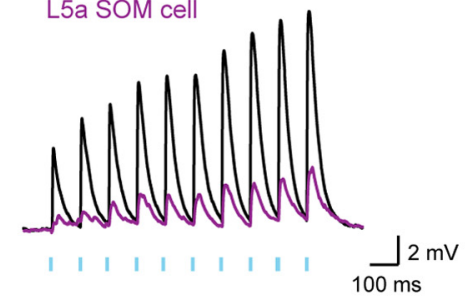

C

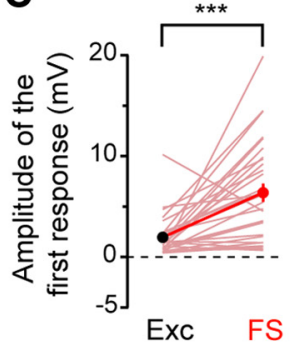

G

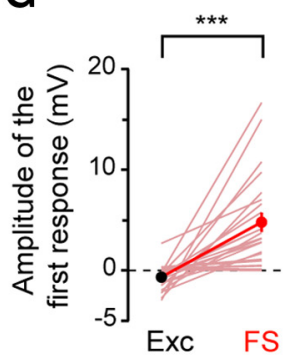

K

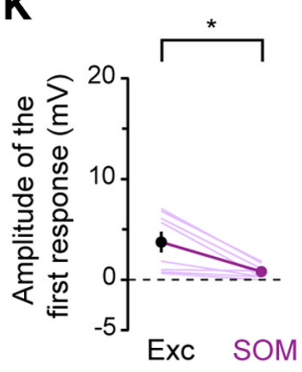

D

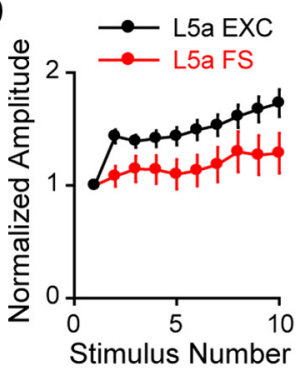

H

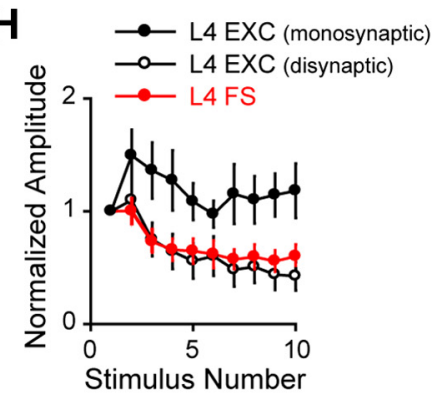

L

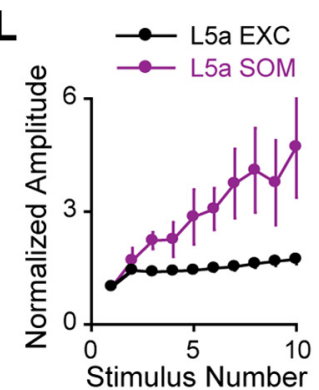

Figure 5. Activation of $\mathrm{L} 6 \mathrm{CT}$ neurons selectively stimulates fast-spiking inhibitory interneurons. Experimental configuration $(\boldsymbol{A}, \boldsymbol{E})$ and sample recordings $(\boldsymbol{B}, \boldsymbol{F})$ from an excitatory neuron and an inhibitory FS interneuron in $\mathrm{L} 5 \mathrm{a}(\boldsymbol{A}-\boldsymbol{D})$ and $\mathrm{L} 4(\boldsymbol{E}-\boldsymbol{H})$. Amplitudes of the first response for $\mathrm{L} 5 \mathrm{a}$ pairs $(\boldsymbol{C} ; n=30$ pairs, $p<0.0001)$ and $\mathrm{L} 4$ pairs $(\boldsymbol{G} ; n=23$ pairs, $p<0.0001)$. Experimental configuration $(I)$, sample recording $(\boldsymbol{J})$ and summary data $(\boldsymbol{K} ; n=8$ pairs, $p=0.0112)$ from an excitatory pyramidal neuron and an inhibitory somatostatin-expressing $G I N$ interneuron in $L 5$ a. Summary data of the short-term synaptic plasticity measured from $L 5$ a and $L 4$ excitatory and inhibitory neurons following $L 6 C T$ photostimulation $(\boldsymbol{D}, \boldsymbol{H}, \boldsymbol{L})$. The data for $L 5$ a pyramidal neurons in $\boldsymbol{L}$ is replotted from $\boldsymbol{D}$.

rons powerfully drive inhibitory FS neurons. In addition to differences in the amplitude of the synaptic input, the properties of the short-term synaptic plasticity depended on the type of synaptic connection (Fig. 5D, H). The responses measured from excitatory neurons facilitated, consistent with previous studies (Ferster and Lindström, 1985). The facilitation may be even greater than measured here as the properties of ChR2 stimulation may lead to an underestimation of any facilitation (Cruikshank et al., 2010). The responses measured from L4 FS interneurons, however, depressed with repetitive stimulation under these experimental conditions. Interestingly, the disynaptic inhibitory responses recorded in L4 excitatory neurons followed a similar time course as the excitatory responses recorded directly from L4 FS cells (Fig. 5H). 
Layer 6 corticothalamic inputs to SOM inhibitory interneurons

To determine whether this preferential activation of inhibitory neurons generalized to other classes of inhibitory neurons, we next recorded from pairs of L5a neurons, composed of one excitatory pyramidal neuron and one SOM GIN interneuron. In contrast to the results seen with FS-pyramid pairs, postsynaptic responses in SOM interneurons were significantly smaller than those in nearby pyramids, and the responses facilitated following repetitive stimulation (Fig. $5 \mathrm{I}-\mathrm{L}$; EXC $3.75 \pm 1.03 \mathrm{mV}$, SOM $0.81 \pm$ $0.24 \mathrm{mV}, n=8$ pairs, $p=0.0112$ ). Our results indicate that, although both FS and SOM interneurons respond to L6 CT stimulation, FS cells receive substantially more excitatory input following L6 CT activation.

\section{Layer 6 corticothalamic inputs evoke action potentials in layer 5a pyramidal neurons}

Given the strong synaptic input onto inhibitory FS cells, we next asked whether L6 CT activation evokes action potentials in L5a pyramidal neurons when FS cells are activated. We recorded from pairs of L5a neurons composed of one excitatory pyramidal neuron and one FS interneuron (Fig. 6A). Increasing the optogenetic stimulation resulted in action potentials being evoked in both $\mathrm{L} 5 \mathrm{a}$ pyramidal neurons and FS interneurons (Fig. $6 B, C$ ). Despite robust activation of FS cells, L5a pyramidal neurons continued to fire action potentials in response to L6 CT neuron activity. Together, these data indicate that L6 CT activation stimulates pyramidal neurons located in an output layer of the cortex.

\section{Discussion}

In the standard cortical model, L6 CT neurons modulate the response gain of cortical neurons via their intracortical axons and their feedback projections to the thalamus (Ahmed et al., 1994; Stratford et al., 1996; Guillery and Sherman, 2002; Binzegger et al., 2004; Sherman, 2005; Sillito et al., 2006; Briggs and Usrey, 2008; Thomson, 2010; Harris and Mrsic-Flogel, 2013). The major target of their intracortical axons is thought to be neurons within L4 (Wiesel and Gilbert, 1983; Callaway, 1998; Binzegger et al., 2004; Douglas and Martin, 2004; Harris and Mrsic-Flogel, 2013). Here, we demonstrate that the intracortical axons of L6 CT cells primarily target L5a rather than L4 and that activation of L6 CT neurons evokes action potentials in L5a pyramidal neurons, as well as FS cells in L4 and L5a, while only weakly exciting or inhibiting L4 excitatory neurons. Here, we stimulated L6 CT neurons selectively and used trains of brief flashes of light to activate these facilitating synapses. The distinct experimental approaches used here likely account for the differences with prior studies using paired recordings or laser scanning photostimulation that have reported weak connections between L6 and L5a pyramidal neurons (Lefort et al., 2009; Hooks et al., 2011).

Anatomical reconstructions of individual L6 CT neurons show two basic types, one with axonal processes terminating within L4 and another with axonal processes ramifying within L5 (Katz, 1987; Zhang and Deschênes, 1997; Thomson, 2010; Feldmeyer, 2012). Although it is largely assumed that the primary target of L6 CT processes are neurons within L4 (Wiesel and Gilbert, 1983; Callaway, 1998; Binzegger et al., 2004; Douglas and Martin, 2004; Harris and Mrsic-Flogel, 2013), without assessing
B

L5a Excitatory cell L5a FS cell

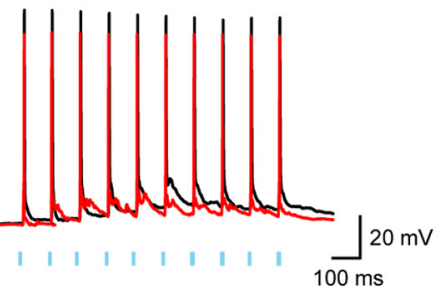

C

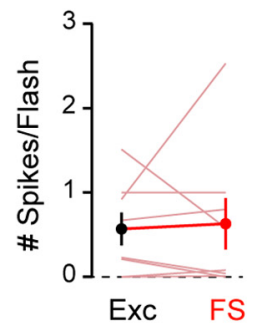

Figure 6. Activation of $\mathrm{L} 6 \mathrm{CT}$ neurons evokes action potentials in $\mathrm{L} 5 \mathrm{a}$ pyramidal neurons and $\mathrm{L} 5 \mathrm{~F} \mathrm{FS}$ inhibitory interneurons. $\boldsymbol{A}$, Experimental configuration. $\boldsymbol{B}$, Example responses from a paired recording of a $L 5$ a pyramid and a $L 5 \mathrm{FS}$ cell. $\boldsymbol{C}$, Average number of action potentials per photostimulation elicited in each pair of $L 5$ a pyramid and L5a FS cell ( $L 5 a$ pyramids: $0.57 \pm 0.19$; L5a FS cells: $0.63 \pm 0.31, n=8$ pairs, $p=0.8105$ ).

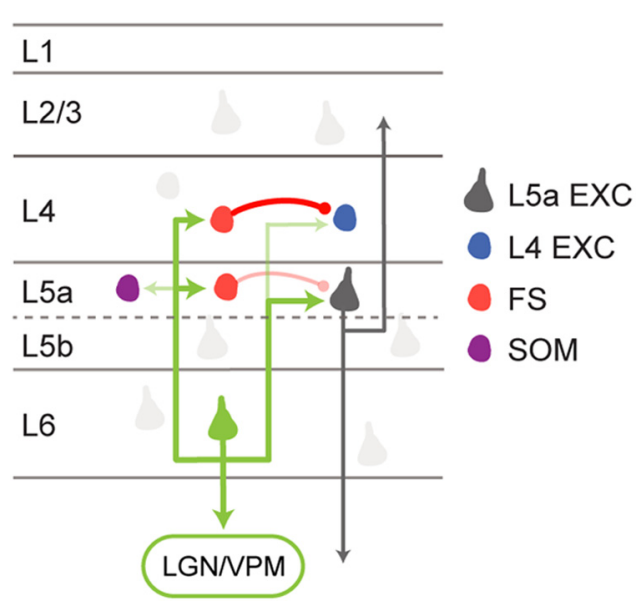

Figure 7. Schematic illustrating the proposed circuit organization. L6 CT neurons provide strong input to L5a pyramidal neurons, as well as FS cells in L4 and L5. Somatostatin-expressing inhibitory interneurons and $L 4$ excitatory neurons receive weak $L 6 C T$ input. The net effect of this synaptic organization is that $\mathrm{L} 6 \mathrm{CT}$ activation evokes action potentials in $\mathrm{L} 5$ a pyramidal neurons while suppressing $L 4$ excitatory cells.

the axonal distribution for the entire population of L6 CT neurons, the contribution to each layer remained unclear. Here, we show that Cre expression in the Ntsr1-Cre mouse line closely corresponds to L6 CT neurons in both visual and somatosensory cortex. By taking advantage of this line, we show that the axonal processes of L6 CT neurons are primarily found within L5a. Furthermore, we demonstrate that activation of L6 CT neurons generates large EPSPs in L5a pyramidal cells while only weakly exciting or even inhibiting L4 excitatory neurons. These results were similar in visual and somatosensory cortex although the disynaptic inhibition measured in L4 excitatory neurons tended to be greater in somatosensory cortex. Together, these data indicate that the synaptic impact of the population of L6 CT neurons is significantly greater in L5a pyramidal neurons than in the primary thalamorecipient layer, L4.

We found that activation of L6 CT neurons strongly activated FS inhibitory interneurons in both L4 and L5a. Furthermore, we show that this input is selective for FS cells as L6 CT neurons provided little input to L5a SOM inhibitory neurons. This selectivity for FS cells suggests that L6 CT activation drives feedforward inhibition via local FS cells and may contribute to the intracortical inhibition that leads to the widespread suppression of visual cortex reported in vivo (Beierlein et al., 2003; Olsen et al., 2012; Bortone et al., 2014). However, although we detected feed- 
forward inhibition in L4 excitatory cells and in L5a pyramids, we found that the direct L6 CT excitatory input activated L5a pyramids. What could account for these differences? Our results highlight several differences in the circuit organization between L4 and L5a excitatory neurons. Because of the high connection probability between L4 FS cells and L4 excitatory neurons, selective activation of FS cells within L4 will generate strong feedforward inhibition in nearby L4 cells. Combined with the weak excitatory input from L6 CT neurons to L4 excitatory neurons, the overall effect of L6 CT activation would be weak excitation or indeed disynaptic inhibition in the excitatory neurons of the major thalamorecipient layer, consistent with our results. In contrast, L5a pyramidal cells receive strong monosynaptic input from L6 CT neurons. Although L5a FS cells are also strongly driven by L6 CT activation, L5a pyramids receive weaker inhibition from these FS cells, consistent with recent work indicating that L5a pyramids receive weaker FS input than L5b pyramids (Lee et al., 2014). It was recently reported that activation of L6 CT neurons drives a class of L6 translaminar inhibitory interneurons (Bortone et al., 2014). Although our experiments did not examine this cellular mechanism directly, we found that L6 CT cells provide excitatory input to L5a pyramids and that, combined with the weak indirect feedforward inhibition, leads to activation of L5a neurons following L6 CT activity. Interestingly, the axonal density of the interlaminar projections of the L6 interneurons dips within L5a, consistent with our results indicating that L5a pyramids receive weaker inhibition than neurons in L4 following L6 CT activation (Bortone et al., 2014). The net effect of L6 CT activation is the generation of action potentials in L5a pyramidal neurons and in both L4 and L5a FS cells but not in L4 excitatory cells (Fig. 7). How these circuits are engaged during sensory perception is not yet clear as photostimulation is unlikely to closely mimic the pattern and distribution of L6 CT activity during perception. Furthermore, the precise behavioral paradigms which activate L6 CT neurons are still not well understood. However, recorded L6 CT neurons do fire at high rates in vivo, suggesting that these facilitating connections will drive L5a spiking under certain behavioral conditions (Grieve and Sillito, 1995; Sirota et al., 2005).

\section{Functional implications}

Our results suggest that excitation of L6 CT cells leads to two simultaneous actions, feedforward inhibition via FS cells and feedforward excitation via L5a pyramidal neurons. Unlike neurons in L4, L5a excitatory neurons project across columns within the cortex (Bureau et al., 2006; Oberlaender et al., 2011) in addition to sending long-range projections out of the cortex. Our results suggest that excitation of L6 CT neurons activates L5a neurons, providing increased input to L2/3 neurons across multiple cortical columns. By inhibiting L4 excitatory neurons and activating pyramidal cells in L5a, L6 CT activity can shift the cortical response from a local one primarily driven by external sensory inputs and L4 neurons to a broader response generated through L5a pyramidal neurons. Together with anatomical studies demonstrating two different morphologies among individual L6 CT neurons, one with axons terminating in L4 and one in L5 (Katz, 1987; Zhang and Deschênes, 1997; Thomson, 2010; Feldmeyer, 2012), our results suggest that these two morphological classes of L6 CT neurons may play different roles in cortical processing.

Here, we have shown that intracortical axons of L6 CT neurons in visual and somatosensory cortex primarily target L5a and that activation of L6 CT neurons elicits action potentials in L5a pyramidal neurons while suppressing L4 excitatory cells. Our data suggest that L6 CT neurons differentially affect activity across cortical layers due to the organization of their intracortical circuits and play multiple roles in cortical processing.

\section{References}

Ahmed B, Anderson JC, Douglas RJ, Martin KA, Nelson JC (1994) Polyneuronal innervation of spiny stellate neurons in cat visual cortex. J Comp Neurol 341:39-49. CrossRef Medline

Ahmed B, Anderson JC, Martin KA, Nelson JC (1997) Map of the synapses onto layer 4 basket cells of the primary visual cortex of the cat. J Comp Neurol 380:230-242. CrossRef Medline

Anderson JC, Douglas RJ, Martin KA, Nelson JC (1994) Map of the synapses formed with the dendrites of spiny stellate neurons of cat visual cortex. J Comp Neurol 341:25-38. CrossRef Medline

Arroyo S, Bennett C, Aziz D, Brown SP, Hestrin S (2012) Prolonged disynaptic inhibition in the cortex mediated by slow, non-alpha7 nicotinic excitation of a specific subset of cortical interneurons. J Neurosci 32: 3859-3864. CrossRef Medline

Beierlein M, Gibson JR, Connors BW (2003) Two dynamically distinct inhibitory networks in layer 4 of the neocortex. J Neurophysiol 90:29873000. CrossRef Medline

Binzegger T, Douglas RJ, Martin KA (2004) A quantitative map of the circuit of cat primary visual cortex. J Neurosci 24:8441-8453. CrossRef Medline

Bortone DS, Olsen SR, Scanziani M (2014) Translaminar inhibitory cells recruited by layer 6 corticothalamic neurons suppress visual cortex. Neuron 82:474-485. CrossRef Medline

Briggs F, Usrey WM (2008) Emerging views of corticothalamic function. Curr Opin Neurobiol 18:403-407. CrossRef Medline

Brown SP, Hestrin S (2009) Intracortical circuits of pyramidal neurons reflect their long-range axonal targets. Nature 457:1133-1136. CrossRef Medline

Bureau I, von Saint Paul F, Svoboda K (2006) Interdigitated paralemniscal and lemniscal pathways in the mouse barrel cortex. PLoS Biol 4:e382. CrossRef Medline

Callaway EM (1998) Local circuits in primary visual cortex of the macaque monkey. Annu Rev Neurosci 21:47-74. CrossRef Medline

Chattopadhyaya B, Di Cristo G, Higashiyama H, Knott GW, Kuhlman SJ, Welker E, Huang ZJ (2004) Experience and activity-dependent maturation of perisomatic GABAergic innervation in primary visual cortex during a postnatal critical period. J Neurosci 24:9598-9611. CrossRef Medline

Cruikshank SJ, Urabe H, Nurmikko AV, Connors BW (2010) Pathwayspecific feedforward circuits between thalamus and neocortex revealed by selective optical stimulation of axons. Neuron 65:230-245. CrossRef Medline

Douglas RJ, Martin KA (2004) Neuronal circuits of the neocortex. Annu Rev Neurosci 27:419-451. CrossRef Medline

Feldmeyer D (2012) Excitatory neuronal connectivity in the barrel cortex. Front Neuroanat 6:24. CrossRef Medline

Ferster D, Lindström S (1985) Augmenting responses evoked in area 17 of the cat by intracortical axon collaterals of cortico-geniculate cells. J Physiol 367:217-232. Medline

Franklin KBJ, Paxinos G (2007) The mouse brain in stereotaxic coordinates. New York: Academic.

Gong S, Doughty M, Harbaugh CR, Cummins A, Hatten ME, Heintz N, Gerfen CR (2007) Targeting Cre recombinase to specific neuron populations with bacterial artificial chromosome constructs. J Neurosci 27: 9817-9823. CrossRef Medline

Grieve KL, Sillito AM (1995) Differential properties of cells in the feline primary visual-cortex providing the cortifugal feedback to the lateral geniculate-nucleus and visual claustrum. J Neurosci 15:4868-4874. Medline

Guillery RW, Sherman SM (2002) Thalamic relay functions and their role in corticocortical communication: generalizations from the visual system. Neuron 33:163-175. CrossRef Medline

Harris KD, Mrsic-Flogel TD (2013) Cortical connectivity and sensory coding. Nature 503:51-58. CrossRef Medline

Hooks BM, Hires SA, Zhang YX, Huber D, Petreanu L, Svoboda K, Shepherd GM (2011) Laminar analysis of excitatory local circuits in vibrissal motor and sensory cortical areas. PLoS Biol 9:e1000572. CrossRef Medline 
Katz LC (1987) Local circuitry of identified projection neurons in cat visual cortex brain slices. J Neurosci 7:1223-1249. Medline

Lee AT, Gee SM, Vogt D, Patel T, Rubenstein JL, Sohal VS (2014) Pyramidal neurons in prefrontal cortex receive subtype-specific forms of excitation and inhibition. Neuron 81:61-68. CrossRef Medline

Lefort S, Tomm C, Floyd Sarria JC, Petersen CC (2009) The excitatory neuronal network of the $\mathrm{C} 2$ barrel column in mouse primary somatosensory cortex. Neuron 61:301-316. CrossRef Medline

Madisen L, Zwingman TA, Sunkin SM, Oh SW, Zariwala HA, Gu H, Ng LL, Palmiter RD, Hawrylycz MJ, Jones AR, Lein ES, Zeng H (2010) A robust and high-throughput Cre reporting and characterization system for the whole mouse brain. Nat Neurosci 13:133-140. CrossRef Medline

Madisen L, Mao T, Koch H, Zhuo JM, Berenyi A, Fujisawa S, Hsu YW, Garcia AJ 3rd, Gu X, Zanella S, Kidney J, Gu H, Mao Y, Hooks BM, Boyden ES, Buzsáki G, Ramirez JM, Jones AR, Svoboda K, Han X, et al. (2012) A toolbox of Cre-dependent optogenetic transgenic mice for light-induced activation and silencing. Nat Neurosci 15:793-802. CrossRef Medline

McGuire BA, Hornung JP, Gilbert CD, Wiesel TN (1984) Patterns of synaptic input to layer 4 of cat striate cortex. J Neurosci 4:3021-3033. Medline

Oberlaender M, Boudewijns ZS, Kleele T, Mansvelder HD, Sakmann B, de Kock CP (2011) Three-dimensional axon morphologies of individual layer 5 neurons indicate cell type-specific intracortical pathways for whisker motion and touch. Proc Natl Acad Sci U S A 108:4188-4193. CrossRef Medline

Oliva AA Jr, Jiang M, Lam T, Smith KL, Swann JW (2000) Novel hippocampal interneuronal subtypes identified using transgenic mice that express green fluorescent protein in GABAergic interneurons. J Neurosci 20: 3354-3368. Medline

Olsen SR, Bortone DS, Adesnik H, Scanziani M (2012) Gain control by layer six in cortical circuits of vision. Nature 483:47-52. CrossRef Medline

Shepherd GM, Stepanyants A, Bureau I, Chklovskii D, Svoboda K (2005) Geometric and functional organization of cortical circuits. Nat Neurosci 8:782-790. CrossRef Medline
Sherman SM (2005) Thalamic relays and cortical functioning. Prog Brain Res 149:107-126. CrossRef Medline

Sillito AM, Cudeiro J, Jones HE (2006) Always returning: feedback and sensory processing in visual cortex and thalamus. Trends Neurosci 29:307316. CrossRef Medline

Sirota MG, Swadlow HA, Beloozerova IN (2005) Three channels of corticothalamic communication during locomotion. J Neurosci 25:5915-5925. CrossRef Medline

Somogyi P (1989) Synaptic organization of GABAergic neurons and $\mathrm{GABA}_{\mathrm{A}}$ receptors in the lateral geniculate nucleus and visual cortex. In: Neural mechanisms of visual perception (Lam DM-K, Gilbert CD, eds), pp 35-62. Woodlands, TX: Portfolio Publishers.

Staiger JF, Zilles K, Freund TF (1996) Recurrent axon collaterals of corticothalamic projection neurons in rat primary somatosensory cortex contribute to excitatory and inhibitory feedback-loops. Anat Embryol (Berl) 194:533-543. CrossRef Medline

Stratford KJ, Tarczy-Hornoch K, Martin KA, Bannister NJ, Jack JJ (1996) Excitatory synaptic inputs to spiny stellate cells in cat visual cortex. Nature 382:258-261. CrossRef Medline

Tamamaki N, Yanagawa Y, Tomioka R, Miyazaki J, Obata K, Kaneko T (2003) Green fluorescent protein expression and colocalization with calretinin, parvalbumin, and somatostatin in the GAD67-GFP knock-in mouse. J Comp Neurol 467:60-79. CrossRef Medline

Thomson AM (2010) Neocortical layer 6, a review. Front Neuroanat 4:13. CrossRef Medline

White EL, Keller A (1987) Intrinsic circuitry involving the local axon collaterals of corticothalamic projection cells in mouse SmI cortex. J Comp Neurol 262:13-26. CrossRef Medline

Wiesel TN, Gilbert CD (1983) The Sharpey-Schafer lecture: morphological basis of visual cortical function. Q J Exp Physiol 68:525-543. Medline

Zhang ZW, Deschênes M (1997) Intracortical axonal projections of lamina VI cells of the primary somatosensory cortex in the rat: a single-cell labeling study. J Neurosci 17:6365-6379. Medline 